\title{
Religião e sexualidade: dilemas contemporâneos brasileiros*
}

\section{Rafael da Silva Noleto**}

Dilemas contemporâneos brasileiros na interface entre religião e sexualidade. Talvez essa seja a discussão central enfrentada no livro recém-lançado por Marcelo Natividade e Leandro de Oliveira. Corroborando interesses mútuos de pesquisa e celebrando uma parceria acadêmica que já se desenvolve há alguns anos, a dupla de antropólogos visa lançar luz à discussão sobre as respostas religiosas brasileiras à emergência de uma comunidade LGBT que é cada vez mais visível na intricada arena de disputas do cenário político contemporâneo no Brasil.

O livro alinhava duas trajetórias de pesquisa que se construíram ( $e$ ainda se constroem) interessadas, por um lado, na discussão sobre as tensas relações entre religiões de base cristã e a diversidade sexual e de gênero (no caso de Marcelo Natividade) e, por outro lado, nas implicações dos processos de subjetivação de sujeitos não heterossexuais quando em diálogo com suas famílias de origem (no caso de Leandro de Oliveira). A partir desses dois eixos de discussão, os pesquisadores encontram nexos para desenvolverem, em conjunto, um trabalho que contempla temáticas muito relevantes para a compreensão do cenário contemporâneo brasileiro no que diz respeito ao debate sobre cidadania LGBT, às dinâmicas de transformação do campo religioso no Brasil após perdas significativas na hegemonia

\footnotetext{
* Recebida para publicação em 8 de abril de 2015, aceita em 4 de dezembro de 2015. Resenha de NATIVIDADE, Marcelo; OliveIRA, Leandro de. Novas guerras sexuais: diferença, poder religioso e identidades LGBT no Brasil. Rio de Janeiro, Garamond, 2013.

** Professor de Antropologia na Universidade Federal do Tocantins (UFT), Doutorando em Antropologia Social pela Universidade de São Paulo (USP), São Paulo, SP, Brasil. rafaelnoleto@usp.br
} 
católica, à inserção de parlamentares cristãos que desafiam mais explicitamente a ideia de laicidade do Estado brasileiro no Congresso Nacional, ao surgimento de igrejas evangélicas inclusivas que ressignificam os sentidos da homossexualidade e outras identidades sexuais não heterossexuais, ao debate em torno das conexões entre família, ethos privado e ethos religioso.

O primeiro capítulo trata de detalhar os procedimentos metodológicos utilizados para a construção da pesquisa e coleta de dados de análise. Os autores empreenderam uma vasta revisão bibliográfica sobre "religião e sexualidade" na antropologia brasileira com intuito de mapear as discussões já realizadas nesse campo, identificando tendências temáticas e lacunas a serem preenchidas. A pesquisa foi também conduzida a partir da coleta de dados em diversos sites e blogs relacionados a instituições ou grupos filiados a certas identidades religiosas, a fim de entender seus posicionamentos públicos acerca da diversidade sexual. $\mathrm{O}$ acompanhamento desses sites proporcionou aos autores a construção de um enorme banco de dados com informações sobre debates que ganharam a esfera pública, especialmente aqueles que colocam em tensão os direitos sexuais e as construções cristãs sobre sexualidade, gênero e família. Além disso, os autores acompanharam cultos em igrejas inclusivas (que não prescrevem o abandono ou "cura" das identidades sexuais não heterossexuais) $e$, por fim, realizaram entrevistas com o intuito de compreender os processos de subjetivação enfrentados por sujeitos autodenominados como LGBT quando em confronto com os ditames religiosos em que foram socializados.

O segundo capítulo é dedicado à revisão bibliográfica do campo sobre "religião e sexualidade" no Brasil. Os autores chamam a atenção para o expressivo número de pesquisas que problematizaram o tema da homossexualidade nos cultos de religiões de matriz africana. Nesse campo, desponta como estudo precursor a etnografia de Ruth Landes (2002), antropóloga norteamericana que foi pioneira ao identificar o lugar privilegiado da homossexualidade nos cultos. Como desdobramentos dessa pesquisa, proliferam etnografias com foco na homossexualidade 
(sobretudo masculina) nos cultos, destacando-se os trabalhos de Peter Fry (1982), Rita Segato (2004) e Patrícia Birman (1995), que reaquecem o debate sobre o assunto nas décadas de 1980 (Fry e Segato) e 1990 (Birman), rediscutindo dados etnográficos de Landes e de seus próprios campos de pesquisa.

No campo das religiões cristãs, os autores constatam que há uma produção etnográfica exígua (p.69) quando comparada às pesquisas nos cultos afro. Nesse sentido, destacam-se as pesquisas de Maria das Dores Campo Machado (1996), Cecília Mariz (1996) e Clara Mafra (1998), que, com ênfases diferentes, ainda nos anos 1990, estavam atentas às discussões sobre "o lugar da mulher na família, na congregação e no espaço religioso" (p. 51) e também sobre o lugar da sexualidade em religiões pentecostais (mais especificamente no caso de Machado). Destacam-se também as pesquisas que tematizaram as problemáticas da sexualidade em contraposição às discussões em torno da família e da religião. Nesse caso, emergem como referências as pesquisas de Luiz Fernando Dias Duarte (2009), Edlaine Gomes (2009), Naara Luna (2009) e Márcia Couto (2001). Entretanto, no campo mais especificamente voltado à problematização da homossexualidade em contraponto às religiões cristãs, é o próprio trabalho de Marcelo Natividade que abre um campo de pesquisa no Brasil ao olhar para as vivências homossexuais (sobretudo masculinas) em tensão com as prescrições pentecostais sobre sexualidade, gênero e família. É nesse contexto que surgem as igrejas inclusivas (objeto de estudo do autor) como fruto de um processo político de visibilização das identidades LGBT no Brasil e da percepção de negociações possíveis entre sexualidade e religião no sentido de compatibilizar as experiências homossexuais, transexuais $e$ travestis com experiências religiosas ambientadas em religiões cristãs.

Buscando compreender os nexos entre religião $e$ homofobia, Natividade e Oliveira dedicam-se à análise dos discursos religiosos na esfera pública, atentando para os pronunciamentos institucionais oficiais e não oficiais de grupos religiosos acerca da diversidade sexual. O material de análise são 
os textos veiculados em sites oficiais de igrejas e blogs de personalidades cristãs - como o escritor Júlio Severo - que elaboram discursos imbuídos daquilo que os autores denominam como "homofobia religiosa", ou seja, um corpo discursivo que desqualifica a diversidade sexual com base em uma autoridade extraída de interpretações conservadoras acerca dos princípios cosmológicos e doutrinários que orientam as religiões cristãs (p. 81). Nesse cenário, despontam inúmeros "ministérios de ajuda" que se dedicam à prevenção de comportamentos que supostamente feririam uma moral cristã como, por exemplo, a homossexualidade. Os ministérios de ajuda atuam no sentido de fornecer informações, sob um ponto de vista cristão, acerca dos "perigos" da homossexualidade, visando a "cura" e a "libertação" das pessoas que vivem "atormentadas" por esse "problema", que é visto como uma perturbação de ordem espiritual. Esses ministérios ganham força em meio a muitos discursos em torno da tramitação do projeto de lei (PL-122/2006) que visava a criminalização da homofobia.

Natividade e Oliveira coletaram discursos que apontam para uma percepção evangélica de que "diálogos entre movimentos sociais, organizações não governamentais e o poder público são retratados como articulação perigosa por propagar "valores não cristãos"” (p. 88). Sob a ótica das igrejas evangélicas, o projeto de criminalizar a homofobia os impediria de afastar "ministros homossexuais" de sua membresia, impondo uma "ditadura gay" às igrejas. Nesse sentido, "obstruir os direitos LGBT, em tais discursos, é uma tentativa de derrotar as influências do demônio na Terra" (p.96). Apesar de identificarem uma convergência entre evangélicos e católicos no sentido de compreender o reconhecimento de direitos LGBT como uma afronta à moral cristã, os autores percebem que a Igreja Católica é menos ruidosa quanto a pronunciamentos públicos sobre homossexualidade no sentido de que não propaga a ideia de "cura" da homossexualidade tal qual muitas denominações evangélicas. Nesse caso, há mais espaço para negociações nas esferas pastorais locais, onde homossexuais católicos podem experimentar relativo 
acolhimento e silenciamento quanto às suas identidades sexuais, desde que gerenciem sua visibilidade. Na maioria dos discursos católicos, as pessoas homossexuais são convidadas a viverem a castidade, pois a homossexualidade é retratada como uma "desordem" que integra a "natureza" dos sujeitos.

No campo das igrejas inclusivas, Natividade e Oliveira identificam duas ênfases ideológicas: de um lado, há as igrejas com um caráter mais histórico, que enfatizam uma teologia inclusiva e um proselitismo mais ativista. Do outro lado, há as igrejas com um caráter mais pentecostal, que enfatizam os códigos de santidade $e$ as prescrições de uma homossexualidade baseada em valores morais cristãos mais amplos como, por exemplo, a monogamia. No primeiro grupo, destacam-se a Igreja Comunidade Metropolitana, Igreja Acalanto e Comunidade Betel, que investem em reinterpretações dos textos bíblicos, no proselitismo religioso em eventos e locais importantes para a comunidade LGBT (como a Parada Gay) e no acompanhamento da tramitação de projetos referentes à luta por direitos no campo sexual e de gênero. Essas igrejas adotam uma postura em que "militância e religião se misturam num discurso que pretende confrontar a homofobia da 'tradição cristã'" (p. 130). No segundo grupo, destacam-se a Igreja Cristã contemporânea, Comunidade Cristã Nova Esperança e Igreja Cristã Evangelho para Todos. A ênfase recai sobre os códigos de santidade e nas linhas de continuidade estabelecidas com $\mathrm{o}$ pentecostalismo mais convencional. A experiência religiosa é valorizada e a retórica da batalha espiritual é evocada para "curar" não a homossexualidade, mas todo e qualquer desejo que fuja a uma moralidade cristã monogâmica ou que endosse a prática do sexo sem compromisso, sem a intenção de "amar" ou constituir um relacionamento estável. Essas diferenciações entre igrejas inclusivas não são estanques, mas permitem perceber as ênfases dadas nesse segmento religioso plural. Como ponto em comum, pode-se dizer que essas igrejas trabalham a partir de uma "pedagogia da aceitação" (p.139), na qual os fiéis passam a aceitar-se como são, pois a homossexualidade é compreendida 
numa perspectiva naturalizante que envolve a criação divina: Deus os fez assim.

Natividade e Oliveira também olham para o campo evangélico mais amplo, identificando as iniciativas de "acolhimento" aos homossexuais por parte das igrejas pentecostais mais conservadoras. Nos discursos que proferem, essas igrejas dizem não discriminar os homossexuais, pelo contrário, afirmam acolhê-los com o intuito de aconselhá-los e colocá-los diante da possibilidade de "cura" da homossexualidade através de um encontro com o poder de Deus. Visam a produção do "ex-homossexual", um sujeito liberto de uma vida pregressa de pecados, que alcançará relativa superioridade moral com o testemunho de sua "cura", não sem enfrentar desconfianças quanto a sua eficácia, pois "embora tomado como sinal do poder transformador de Deus, seu relato desperta também uma atenção e suspeita" (p.171). Os autores concluem que, na retórica do acolhimento, "esses discursos procuram conciliar o princípio do 'amor ao próximo' com uma atitude radical de repúdio à diferença" (p.159-160).

As experiências dos sujeitos LGBT com suas redes religiosas de origem também são analisadas no livro. A partir dos depoimentos de diversos interlocutores (especialmente homens, pois os autores sinalizam para maior frequência deles nas igrejas inclusivas), a pesquisa mostra como "o sentimento de temor diante do desejo homossexual e o medo do pecado ensejam a derradeira dúvida acerca do amor de Deus" (p.192). Os entrevistados compartilham suas experiências de exclusão nos contextos religiosos em que foram sociabilizados, apontando como marcantes os momentos em que foram alijados de seu protagonismo ministerial, sendo relegados a "estar no banco da igreja", ou seja, a deixar de exercer cargos eclesiais por conta de sua condição de "impureza" (p.188-189). Nesse sentido, "o sujeito que adere a uma identidade LGBT não pratica um pecado, ele é o pecado" (p.193). A partir da socialização em ambientes religiosos em que o discurso não apenas patologiza, mas demoniza a homossexualidade, esses sujeitos desenvolvem conflitos interiores 
diversos com variados graus de gravidade, ensejando desde conflitos familiares e congregacionais até tentativas de suicídio. É nesse ponto que os autores consideram que as falas de seus entrevistados sobre seus próprios conflitos interiores não devem ser compreendidas somente como resultado de tensões intrapsíquicas, mas

como um indicador dos mecanismos de sujeição a que os entrevistados foram submetidos ao longo de suas trajetórias, para os quais a socialização religiosa colabora na modelação de sentimentos, emoções, percepções, visões de mundo, oferecendo recursos cosmológicos e doutrinários para a interpretação do desejo homoafetivo (p.209-210).

Os autores se debruçam sobre as experiências de passagem dos sujeitos entre as igrejas conservadoras e as igrejas inclusivas. Nesse segmento, "a verdade da sexualidade, fundante da identidade, passará a ser percebida como condizente com a verdade de Deus" (p. 233). Esses grupos inclusivos proporcionam aos sujeitos LGBT a retomada de uma vida congregacional, o exercício de atividades rituais, o acesso a cargos eclesiais e, principalmente, a experiência com uma espiritualidade que aceita e valoriza a diversidade sexual (p.216). Outro dado importante é o fato de que os autores buscaram entender a experiência de mães cristãs que possuem filhos homossexuais que frequentam igrejas inclusivas. Identificaram que há graus diferenciados de aceitação das identidades sexuais de seus filhos. As mães elaboram narrativas que tentam encontrar pontos de contato entre os discursos cristãos tradicionais e os discursos inclusivos. Algumas compreendem melhor a homossexualidade de seus filhos a partir da convivência anterior com pessoas homossexuais em outras redes de sociabilidade. Por outro lado, os filhos não interpretam as situações de exclusão ou rechaço vividas nas relações intrafamiliares como "homofobia" ou "preconceito"; compreendem essas situações de forma mais pessoalizada, sublinhando a maior ou menor aceitação de seus familiares 
quanto as suas orientações sexuais (p. 258). Essas situações tensas vividas com familiares são, muitas vezes, interpretadas como "cuidado" e "zelo" (p.260). Do ponto de vista de muitas mães, a adesão religiosa a uma igreja inclusiva é, de certo modo, positiva, pois incentiva o comedimento sexual, o estabelecimento de relacionamentos estáveis e a adoção de uma homossexualidade discreta (p.266).

O livro representa uma grande contribuição para a antropologia brasileira no sentido de que desvela um cenário religioso plural em tensas negociações com as identidades sexuais emergentes como sujeitos de direitos. Além de focar em experiências masculinas com a homossexualidade, a pesquisa traz ainda depoimentos de lésbicas (que são mais visíveis em igrejas inclusivas com lideranças lésbicas) e travestis, embora reconheça que esse campo das identidades sexuais e de gênero femininas necessite de maior atenção em pesquisas futuras. As narrativas mais pessoalizadas trazidas nos capítulos finais da obra enriquecem o debate e evidenciam como as religiões operam no sentido promover exclusões baseadas em interpretações teológicas unilaterais e universalizantes. As narrativas dos sujeitos são, em muitos casos, comoventes porque se constroem na intersecção entre a impossibilidade de se relacionar com Deus, com a família de origem e com as pessoas por quem possuem desejos de ordem afetiva e sexual. Certamente, um trabalho que merece ser lido tanto por aqueles que pesquisam sexualidade quanto por pesquisadores que se dedicam à religião como matéria de estudos.

\section{Referências bibliográficas}

BIRMAn, Patrícia. Fazer estilo criando gênero. Rio de Janeiro, Relume Dumará/EDUERJ, 1995.

Couto, M. T. O pluralismo religioso intrafamiliar e as transformações recentes nos campos da família e da religião. Teoria \& Sociedade 8, 2001, pp. 78-97. 
DuARTE, Luiz Fernando Dias; GomES, Edlaine de Campos. Três famílias: identidades, trajetórias transgeracionais nas classes populares. Rio de Janeiro, FGV, 2008.

DUARTE, Luiz Fernando Dias et alii. (orgs.) Valores religiosos e legislação no Brasil: a tramitação de projetos de lei sobre temas morais controversos. Rio de Janeiro, Garamond, 2009.

FRY, Peter. Para inglês ver: identidade e política na cultura brasileira. Rio de Janeiro, Zahar, 1982.

LANDES, Ruth. A cidade das mulheres. Rio de Janeiro, Editora UFRJ, 2002. [1940]

LUNA, Naara. Simbólica do parentesco e religião no Ocidente: uma abordagem histórico-cultural. In: GOMES. E. C. (org.). Dinâmicas contemporâneas do fenômeno religioso na sociedade brasileira. São Paulo, Ideias e letras, 2009, pp.75-99.

MAFRA, Clara. Gênero e estilo eclesial entre os evangélicos. In: FERNANDES, R. C. et al (orgs.). Novo Nascimento: Os evangélicos em casa, na igreja e na política. Rio de Janeiro, Mauad, 1998, pp.224262.

MARIZ, Cecília Loreto; MACHADO, Maria das Dores Campos. Pentecostalismo e redefinição do feminino. Religião e sociedade 17(12), 1996, pp.140-159.

NATIVIDADE, Marcelo; GOMES, Edlaine. Para além da família e da religião: segredo e exercício da sexualidade. Religião e sociedade 26(2), 2006, pp.41-58.

SEgATO, Rita. Inventando a natureza: família, sexo e gênero no Xangô do Recife. In: MouRA, C. E. M. (org.). Candomblé: religião do corpo e da alma: tipos psicológicos nas religióes afro-brasileiras. Rio de Janeiro, Pallas, 2004, pp.45-102. [1986] 